\title{
Application of Queuing Theory to Optimize Waiting- Time in Hospital Operations
}

\author{
Deepak Yaduvanshi \\ Pulmonology Critical Care Manipal Hospital, Jaipur, India \\ Email: drdeepak98@gmail.com
}

Ashu Sharma

School of Business Management

Narsee Monjee Institute of Management Studies (Deemed-to-be-university), India

Email: Ashu.Sharma@sbm.nmims.edu

Praful Vijay More

School of Business Management

Narsee Monjee Institute of Management Studies (Deemed-to-be-university), India Email: moreprafulv@gmail.com (Corresponding Author)

\begin{abstract}
Waiting time is inherent to the healthcare service sector in India and a major challenge faced by almost every big hospital is queuing. Long waiting time can be a reflection of inefficiency in hospital operations. The out-patient department (OPD) has the biggest queue as compared to other departments in hospital operations. This study comprises of in-depth analysis of OPD from different dimensions. Like in many big hospitals across India, the OPD of Fortis Escorts Hospital in Jaipur, India is managed using experience and rule of thumb rather than strategic research-based techniques such as queuing theory. The Fortis Escorts Hospital in Jaipur receives a large number of patients each day which results in longer waiting time for patients due to long queues. To address this challenge, a SWOT analysis was conducted for the OPD of Fortis Escorts Hospital Jaipur (FEHJ) which resulted into dissecting the queuing problem and coming out with solutions knowing where the hospital operations can excel and where there is a scope of improvement to make the working and processes better. Additionally, after examining the problem analytically and applying queuing theory, measures were suggested to improve the delay points and make the OPD more efficient in order to gain a high patient satisfaction rating.
\end{abstract}

Keywords: queuing theory, OPD, waiting time, hospital operations, SWOT, patient satisfaction

\section{INTRODUCTION}

Hospital services operations particularly, the outpatient department plays a crucial role in providing quality healthcare for multi-specialty hospitals (Carman, 1990). The outpatient department (OPD) often acts as a profit centre in hospital operations not only for investing in new technology but also to curb losses on inpatient services (Green, 2006). However, despite the importance of OPD, hospitals fail to address complaints regarding long waiting time caused majorly due to observable queues which result in patient dissatisfaction (Kim et al., 2009). Thus, hospital service operations should have a smooth flow to satisfy the patient's expectations by redesigning their systems and adapting to the best practices and tools with improved processes (Natrajan, 2006) which has a huge scope in developing economies such as India (Natchair et al., 1994).

The OPD of a hospital acts as a bridge between hospital and community, hence it is very important to plan the OPD with the idea of maximizing the utilization and quick turnover. (McQuarrie, 1983). It is imperative to have effective co-operation between the medical services and the support line services catering to the OPD requirements (Kritchanchai, 2012). The interpersonal skills of the medical personnel, availability of medicine, hospital infrastructure and medical information plays an important role in managing OPD and create a positive influence on patient satisfaction (Natarajan, 2006). Hence, it is necessary to focus on optimizing waiting time in hospital operations for the benefit and wellbeing of patients.

Due to poor hospital service operations, patients tend to spend a lot of time getting the services they need (Dellaert et al., 2015; Lohlun et al., 2015). Long queues are an indication of lack of coordination, poor management, and insufficient resources, which affects the quality of services in hospital operations and reduce patients' satisfaction (Basta et al., 2016; Bringedal, 2016; Bachmann and Barron, 1997). Given the role of waiting time in improving service quality for the higher satisfaction of patients, it is necessary to review it as one of the most common problems in hospital service operations (Benson et al., 2001; Bleustein et al., 2014).

Application of queuing theory for analysis and modeling of processes that involves waiting lines is used widely in industries for optimizing the supply of fixed resources at variable demand conditions, however, the healthcare industry views itself differently from other industry (Kritchanchai, 2012). The hospital operations managers should be aware of the status of business processes to improve operational performances and reduce the waiting time (Hall et al., 2006). There are several analytical tools for understanding the complexity of a system's performance, 
among which the queuing theory is a tool to analyze systems which include queues and consist of clients, servers, and queues (Kay et al., 1996; Van Wyk and Walubo, 2014). Queuing theory is a scientific approach to minimize system inefficiencies and increase the patients' satisfaction (Bahadori et al., 2014; Mayhew and Smith, 2008). The hospital operations managers can increase patients' satisfaction by making the right decisions through a proper understanding of the queuing theory and variables related to the patients' waiting time (Komashie et al., 2015).

There is a lot of research available on queuing analysis related to a variety of hospital services such as cardiac care units, operating rooms, and emergency services. However, due to a lack of real-world validation, many proposed queuing models have yet to be adopted by hospital authorities. Therefore, there is a need to explore the utility and implications of queuing theory by validating a simple queuing model in a busy hospital of India. This paper through an actual OPD study of a large multi-specialty hospital shows how improvements in out-patient flow through streamlining of OPD processes can be achieved using SWOT analysis and queuing model. The study was conducted in a multi-specialty hospital called Fortis Escorts Hospital, Jaipur (FEHJ) which is a NABH accredited hospital with 250 beds and spread over an area of 3.67 acres in the capital of one of the largest states in India. Due to a wide variety of healthcare services provided by FEHJ, it took a long time for patients arriving at OPD to meet the concerned specialist leading to the formation of the queue. Naturally, one of the major grievances among the majority of the patients was the time they spend while waiting in OPD. The key aim of the paper is to aid hospital service operations at FEHJ in identifying bottlenecks in service operations and potential areas for improvement in the system, with the objective of optimizing patients waiting time, thereby allowing a higher flow of patients in OPD using queuing model.

The flow of the paper is organized in terms of objectives which are as follows. First, the complete process flow of the OPD is studied which is our first objective. It is followed by SWOT analysis to identify areas where time is consumed making it second objective. The third objective is to understand how patients perceive waiting time through survey method. Then, we conduct time study in different OPD's as part of the fourth objective and lastly, using queuing model, we calculate the waiting time in different OPD's. Finally, based upon results obtained, we draw some conclusions and discuss some implications of our findings along with the limitations of the study.

\section{LITERATURE REVIEW}

There have been studies on waiting time in hospital operations focused on the doctor and patient consultations in general hospitals (Park, 2001) which found that the factors influencing waiting time were characteristics of healthcare providers, consultation and patient's characteristics (Hwang, 2006). The classification of studies on applying queuing theory to healthcare service can be based upon waiting time and utilization analysis (Yeo et al., 2014), which can be further classified into those on reneging (Broyles and Cochran, 2007), variable arrival rate (Worthington, 1987), priority queuing discipline (Fiems et al., 2005) and blocking
(Koizumi et al., 2005); whereas studies on system design with respect to queuing (Green et al., 2006; Park and Kwag, 2009) are classified into cost minimization (Gorunescu et al., 2002) and blocking. Based on size of the system (Hall et al., 2013), studies have been conducted at department-level which includes Departments of Internal Medicine (Hwang, 2006), Orthopaedics (Yeo et al., 2014), Emergency Room (Kim et al., 2009;Mandelbaum et al., 2012), Radiology (Park and Kwag, 2009) and MRI (Green and Savin, 2008); while those conducted at healthcare center-level had the whole outpatient department (Park, 2001; Ko, 2010; Kim et al., 2008).

The analysis of waiting time in healthcare systems can be approached mathematically using queuing theory (Ozcan, 2006). It is been established that queuing theory can be used for improving patient waiting time in hospital operations by an extensive review of the literature (Green, 2006a; mcquarrie, 1983; Siddhartan et al., 1996). There is already large publication involving the application of queuing theory to service operations in hospital settings (Adele and Barry, 2005; Ivalis and Millard, 2003; Vasanawala et al., 2005). Unfortunately, this vital tool is underutilized in most hospital operations across India. There has also been extensive research on queuing analysis to enhance performance at various hospital departments (Green, 2002; Kim et al., 1999) and emergency departments (Green et al., 2006). Most hospital operations involve appointment system and the use of queuing is done in either of the two ways i.e. First-in-firstout or different classes of patients solely based on priority for e.g. In case of an emergency which automatically gets first priority before others (Adele and Barry, 2005). It is indeed possible to optimize patient waiting time on a priority basis by addressing the issue of which patient requires shorter service time (mcquarrie, 1983). The studies on models of queuing theory are provided by Green (2006a) and analysis of the effect of waiting times on patients in the Emergency Department is given by (Siddhartan et al., 1996). The flow of patients in a queue can lead to good patient flow if the queuing is minimized whereas queuing delays can lead to patient suffering causing poor patient flow (Hall et al., 2006). The demand for health care services can be determined by effective resource allocation and capacity planning (Murray, 2000). Based on specific probability assumptions, queuing theory can be used to provide an exact or approximate estimate of performance measures (Daulatani et al., 2016). However, the results are approximated because the assumptions rarely hold (Cochran et al., 2006).

Lewis, Bernard \& Booms (1983) have defined that service quality is a measure of the gap between customer expectations and perceptions, and meeting customer expectations on a consistent basis. The outcome of the evaluation process is defined as perceived service quality and consumers tend to compare his expectations with the services received (Gronroos, 1984). Parasuraman et al., (1991) emphasized the use of SERVQUAL as a diagnostic methodology for addressing service quality shortfalls and strengths. SERVQUAL has been extensively used to measure service quality in a variety of service sectors such as healthcare (Carman, 1990; Kilbourne et al., 2004). Service quality focuses on meeting customers' needs and requirement and how well the delivered service meets the expectations of customers (Lewis and Booms, 1983). Customer dissatisfaction occurs when expectations are a higher and 
perceived quality of service is less than satisfactory (Parasuraman et al., 1988; Lewis and Mitchell, 1990).

Effective external communication creates realistic consumer expectations and enhances consumer perceptions which offset other service quality problems as well (Parasuraman et al., 1985). Making patients entering OPD systems aware of the apparent services could improve service quality perceptions and increase awareness about hospital service operations (Kilbourne et al., 2004). Patients are likely to perceive service delivered in a favorable way by segmenting on the basis of their service quality expectations which will ultimately lead to higher customer satisfaction. (Lewis et al., 1990)

External communications affect not only consumer expectations about a service but also consumer's perceptions of the delivered service (siddhartan, 1996). Consumers' quality perceptions of the service quality model are influenced by a series of distinct gaps occurring on the marketers' side (itumalla et al., 2014). A key challenge for researchers is to devise methods to measure these gaps accurately (parasuraman et al., 1985). This paper intends to address the gap between actual service delivery and external communication about the hospital which affects service quality from a patient's point of view.

\section{RESEARCH DESIGN}

In service operations management, it is always recommended to use a standard methodology that enables to understand the current processes, determine the desired changes and improve them. The present paper aims at optimizing the performance of OPD department using queuing theory and increase patients' satisfaction. Using indepth analysis of OPDs from different dimensions, the objectives involved in the study are listed as follows:

1. To study the complete process flow of the OPD at Fortis Escorts Hospital, Jaipur.

2. To identify areas where a patient's time is consumed by performing a SWOT analysis of the existing OPD.

3. To find out patient's perception of delay in OPD through a satisfaction survey.

4. To do time study on different OPD stations at Fortis Escorts Hospital, Jaipur.

5. To calculate the waiting time of patients in different OPD stations using queuing model.

\section{RESEARCH METHODOLOGY}

The management of patient flow is an important element in improving the efficiency of hospital service operations. It requires handling the arrival of patients, service process and queuing process, which directly impacts the delivery of healthcare services. Since it is a study which emphasizes the legal phenomenon of cause and effect of a condition, it is a positivist social science research done by cautiously using the empirical observations. The research methodology used in this paper is a case study due to the indepth examination of an extensive amount of information about very few units or cases across a single time frame. To optimize waiting time in hospital operations using queuing theory, the study design is a time study. The study was stretched around a week of observation for the OPD working pattern and the probable delay points, data collection of time consumed at each step involved in getting a consultation done in the OPD. The instrument used for the analysis was questionnaire and time study analysis were done for getting the results of the survey.

The study was conducted in two dimensions namely, Objective and the Subjective approach. In objective assessment, it was observed that for how much time the patients waited in the queue, the time they spent at the registration counter, the time consumed in reaching the OPD and the waiting time in the OPDs for consultation, etc. The initial part of the objective assessment involved identifying the key informant in OPD to get information about a general overview of the outpatient system. After that, the collection of more data and information related to this study was analyzed using a queuing model to optimize the waiting time and arrival pattern of the outpatient department for objective assessment. This data was then used for analyzing the situation and derive an insight to give recommendations which could reduce the waiting time for patients. The subjective approach included the patients' perception about the delay, the reasons behind the delay, the psychology and opinion regarding the promptness in the registration time, getting the consultation, type of investigation done, promptness in giving the investigation report, etc. and the number of possible reasons of the delay. The observations for subjective assessment were collected through field visits and to see directly outpatient service an arrival pattern of patients in OPD of FEHJ.

\section{CONCLUSIONS}

The results of the study are obtained by addressing each objective as follows.

\subsection{The Complete Process Flow of the OPD}

The first point of contact between the patient and the hospital staff is OPD, which acts like a mirror reflecting the functioning of the hospital operations. Patients visit OPD for variety of purpose like, consultation, day care treatment; investigation, referral, admission, and post-discharge followups which generate the first impression of the hospital service operations. The process flow at Fortis Escorts Hospital OPD is shown in Figure 1 given below.

OPD is a critical process for any hospital and analysis of OPD helps to not only identify but also eliminate unnecessary movements for efficient and effective patient care. Assessment of the OPD layout can lead to a reduction in overcrowding and consultation delay which drastically decreases the efforts, patients need for treatment and/or routine check-ups. A more detailed process analysis of the OPD can be seen in Figure 2 given below. 


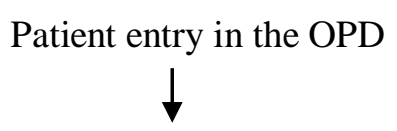

Measuring the time a patient has to stand in the queue

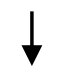

Measuring the time the patient takes at the OPD desk

(This time is studied under 2 purviews, for the patients who are registered and for the patients who are not registered)

Measuring the time taken by the patient to reach the concerned OPD

Measuring the waiting time of patient in OPD

Figure 1 Process flow of fortis escorts hospital OPD

Patient entry in the hospital

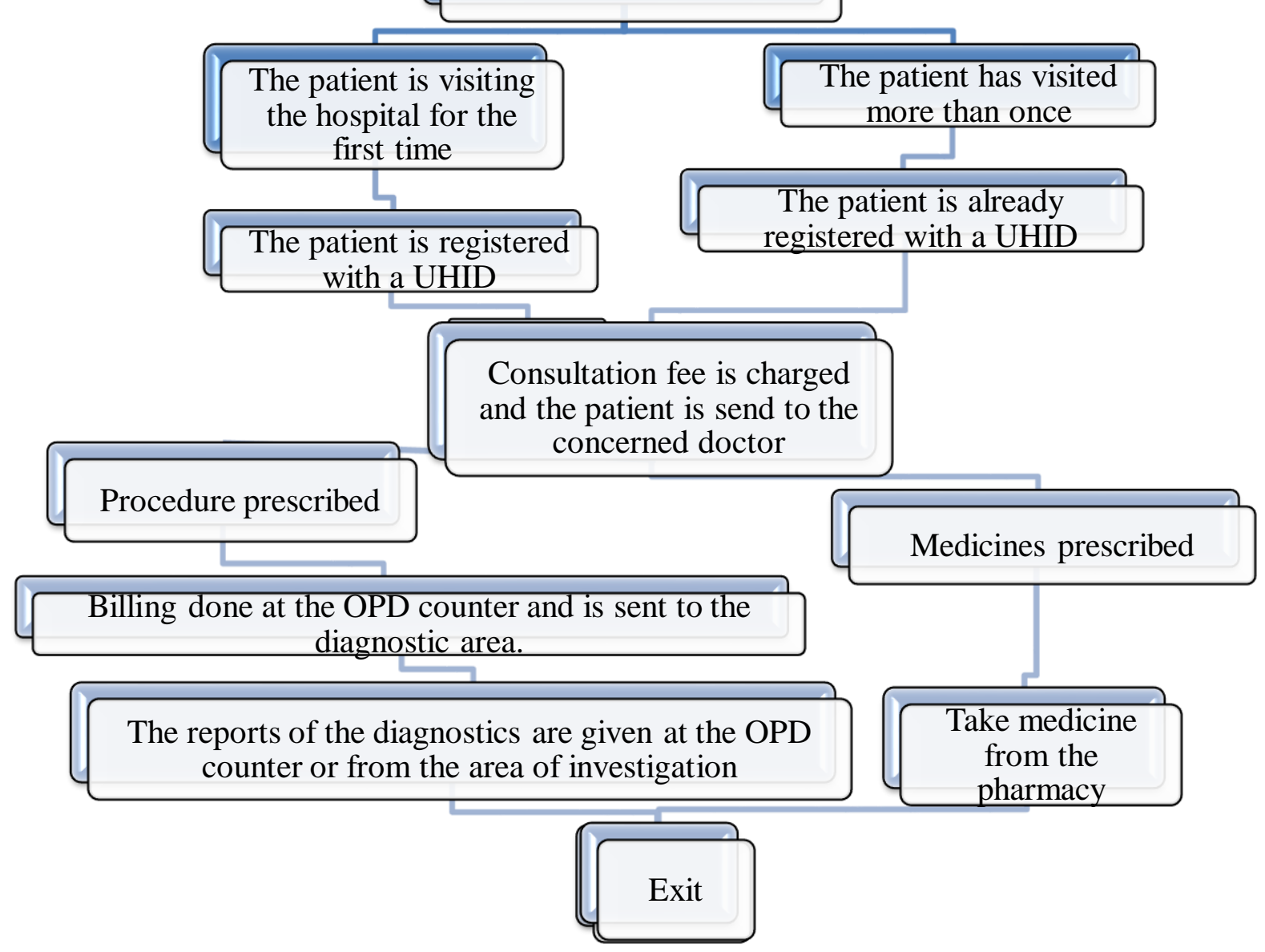

Figure 2 Process analysis of fortis escorts hospital OPD 


\subsection{Areas Where Patient's Time is Consumed}

After understanding the process flow of the outpatient department, there is a need to have a holistic view of OPD at Fortis Escorts Hospital Jaipur. The SWOT analysis is an appropriate method for identifying and assessing the strengths and weaknesses, opportunities and threats in order to optimize the development opportunities of hospital operations. Although SWOT analysis is intended for other industries, it is increasingly important for the healthcare sector, especially in hospital operations. SWOT analysis combines the findings of strategic analysis of the external and internal factors that stimulate the successful operations of the OPD at Fortis Escorts Hospital Jaipur (FEHJ).
Factors which influence strength for OPD at FEHJ are its strategic location of the reception area, well-placed stations all around the area, knowledgeable and trained staff responding to patients need, etc. However, despite that there are still few but relevant weaknesses such as queuing issues at the registration counter of OPD due to non-availability of forms, registered and non-registered patients forming the same queue, less sitting capacity, etc. These factors possess threats for hospital operations at OPD in terms of time constraints for patients leading to lower satisfaction but also provide opportunities for better management of the queues in OPD at FEHJ. The results of the SWOT analysis of OPD at Fortis Escorts Hospital, Jaipur are presented in Figure 3 given below.

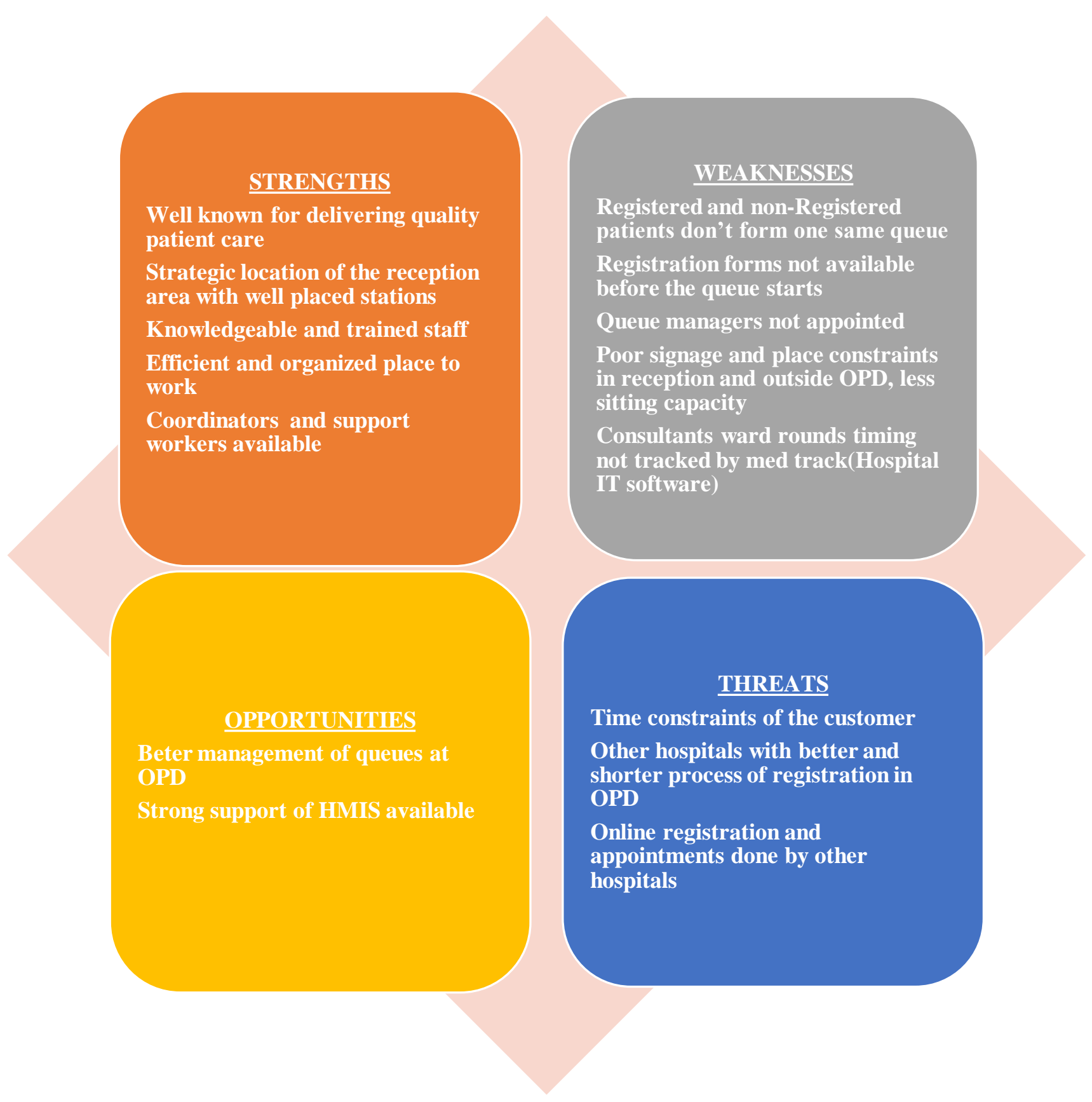

Figure 3 SWOT analysis of OPD at fortis escorts hospital, Jaipur 
Table 1 Areas where patient time is wasted

\begin{tabular}{cccc}
\hline S. No & Problem area identified & Average wait time (minutes) & Projection of time which can be saved \\
\hline 1 & $\begin{array}{c}\text { Lack of a proper system for informing } \\
\text { first-time visitors about registration }\end{array}$ & 9.86 & $43.86 \%$ \\
\hline 2 & $\begin{array}{c}\text { Delay due to technical errors such as } \\
\text { the problem with printers, etc. }\end{array}$ & 2 & $11.12 \%$ \\
\hline 3 & $\begin{array}{c}\text { Delay due to receptionist taking } \\
\text { appointments on the phone }\end{array}$ & 0.5 & $3.87 \%$ \\
\hline
\end{tabular}

An objective assessment of 50 patients was done by observing how much time the patients waited in the queue, the time spent by patients at the registration counter, the waiting time in the OPDs for consultation, etc. The study reveals the average waiting time spent by the patients at different OPD and expresses their view towards the hospital service operations. The study also sheds light on the total time consumed by different OPDs.

Pareto's 80:20 Principle, which is a law applicable to all fields of study, states that only $20 \%$ of the reasons generate $80 \%$ delay in operations. Hence, it is necessary to focus on those critical and few reasons rather than diverting attention towards $80 \%$ trivial issues. A retrospective analysis in consultation with doctors for delays in OPD of hospital operation helped in identifying major reasons for delay and recommendations were provided to reduce the waiting time of patients in OPD.

Following Pareto's principal, few critical areas as shown in Table 1, were identified which caused delay and addressing these issues could possibly save more than half of patients waiting time.

\subsection{Patient's Perception of Delay in OPD}

Patients arriving in the OPDs of hospitals are responsible for spreading the good image of the hospital and therefore patient satisfaction is equally important for hospital management. Due to continuous changes in hospital operations, it is difficult to maintain patients' satisfaction as a top priority for OPD which is the first interaction for hospital management. An OPD is a place where nonemergent ambulatory medical care is provided under the supervision of a physician and the attitude of health care providers has its own impact on the satisfaction level of patients. More the positive attitude more the patient is satisfied, patient satisfaction also depends on 'nursing care' because nurses are involved in almost every aspect of patient care in hospital operations.
In this study, it has been observed at $80 \%$ of patients rated their level of satisfaction at OPD as Good, $6 \%$ patients were dissatisfied with the services at OPD and remaining $14 \%$ patients felt average level of satisfaction at OPD. While conducting this study, we found health services make hospital operations more sensitive and alert to patient needs. Many instances in which patients were eager about the services they had received in the hope that some action would be taken determining their level of satisfaction.

\subsection{Time Study on Different OPD Stations}

OPD indicators related to services in hospital operations are described as follows. The outpatient department is open from 9.00 a.m. till 5.00 p.m. working a total of 9 hours per day. It must be noted that for the purpose of this study, the emergency department which remains open even after 5.00 p.m. is not included. The patient arrival rate each day at OPD is calculated by dividing the average patients per day i.e. 288 by 9 hours of work resulting 32 patients per hour. The service rate of patients was calculated after interviewing with the doctors, one doctor averagely takes 8 minutes to treat one patient which implies that a doctor can see 7 patients per hour.

The registration time is the time consumed at the registration desk and the registration turnaround time (TAT) is the time from when the patient enters OPD until the patient was registered. Patient flow at different OPD with average waiting time can be seen in Table 2 and the registration TAT came out to be 12 minutes out of which the average registration time was 3 minutes, so we decided to find out the results for OPD 2 without registration using the mean interarrival time as 9 minutes. The waiting time hugely depends upon the flow of patients in different OPDs and thus the average waiting time of patients before seeing a doctor was calculated OPD wise.

Table 2 Average waiting time in different OPDs

\section{S. No \\ OPD}

The average time is taken before seeing a doctor (Minutes)

\begin{tabular}{cccc}
\hline 1 & Cardiac OPD & $66.66 \%$ & 16 \\
\hline 2 & OPD2 & $19.62 \%$ & 61 \\
\hline 3 & OPD1 & $7.84 \%$ & 9 \\
\hline 4 & Paediatric OPD & $5.88 \%$ & 7.5 \\
\hline
\end{tabular}

Source: Fortis escorts hospital, Jaipur 


\subsection{The Waiting Time of Patients in Different OPD Stations}

There is always random arrival of patients for receiving healthcare services and that require immediate availability of service, but they should be able to wait in line with patience when the hospital services are operating at peak capacity. Due to the dynamic nature of hospital service operations, it is often difficult to predict the arrival of no. of patients and time taken for consultation at any given moment.

The goal of the queuing theory is to reach an optimal equilibrium between the arrival rate and service rate of patients in OPD for the smooth functioning of hospital operations. The input parameters for queuing model $\mathrm{M} / \mathrm{M} / 1$, given in Table 3 are calculated using a number of patients in the system denoted by $n$, average arrival rate i.e. no. of arrivals per hour denoted by $\lambda$ and average service rate per server denoted by $\mu$. The symbols and formulae to be used are given in Table 4.

While using queuing model, only 3 OPDs with the highest patient flow i.e. Cardiac, OPD, and OPD2 were considered, comparing the number in queue, waiting time of patients in the queue, waiting time of patients in the system and number in the system all calculated using queuing formulae for modeling. The mean inter-arrival time is exponentially distributed whereas service time of different OPDs is uniformly distributed, hence average is considered for sensitivity analysis of different OPDs as shown in Table 5.

$\underline{\text { Table } 3 \text { Input parameters for queuing model }}$

\begin{tabular}{cc}
\hline $\begin{array}{c}\text { Parameter M/M/1 } \\
\text { (exponential service } \\
\text { times) }\end{array}$ & Value \\
\hline Arrival rate $(\lambda)$ & 32 patients per hour \\
\hline Service rate $(\mu)$ & 8 patients per hour \\
\hline No. of OPDs & OPD1, OPD2, Cardiac OPD \\
& and Paediatric OPD \\
\hline
\end{tabular}

Table 4 Symbols and formulae to be used in the calculation of M/M/1 Model

\begin{tabular}{ccc}
\hline Symbol & Meaning & $\begin{array}{c}\text { Formulae in M/M/1 } \\
\text { model }\end{array}$ \\
\hline $\mathrm{P}$ & Operation rate & $\rho=\lambda / \mu$ \\
\hline $\mathrm{Wq}$ & $\begin{array}{c}\text { Average waiting time in a } \\
\text { queue }\end{array}$ & $\mathrm{Wq}=\rho / \mu-\lambda$ \\
\hline $\mathrm{Ws}$ & $\begin{array}{c}\text { Average entire time in a } \\
\text { system }\end{array}$ & $\mathrm{Ws}=1 / \mu-\lambda$ \\
\hline $\mathrm{Lq}$ & $\begin{array}{c}\text { Average number of } \\
\text { patients in a queue }\end{array}$ & $\mathrm{Lq}=\rho N \mu-\lambda$ \\
\hline $\mathrm{Ls}$ & $\begin{array}{c}\text { Average number of } \\
\text { patients in a system }\end{array}$ & $\mathrm{Ls}=\lambda / \mu-\lambda$ \\
\hline
\end{tabular}

Table 5 Sensitivity analysis of different OPDs

\begin{tabular}{ccccccc}
\hline OPD & $\begin{array}{c}\text { Mean inter-arrival } \\
\text { time } \\
\text { (minutes) }\end{array}$ & $\begin{array}{c}\text { Service time } \\
\text { (minutes) }\end{array}$ & $\begin{array}{c}\text { Number in } \\
\text { the queue } \\
\text { Lq }\end{array}$ & $\begin{array}{c}\text { Wait in the } \\
\text { queue } \\
\text { Wq } \\
\text { (minutes) }\end{array}$ & $\begin{array}{c}\text { Wait in the } \\
\text { system } \\
\text { Ws } \\
\text { (minutes) }\end{array}$ & $\begin{array}{c}\text { Number in } \\
\text { the system } \\
\text { L }\end{array}$ \\
\hline Cardiac & 10 & 8 & 1.608 & 16.08 & 24.08 & 2.408 \\
\hline OPD I & 12 & 11 & 5.045 & 60.54 & 71.54 & 5.961 \\
\hline OPD II & 8 & 6 & 1.135 & 9.08 & 15.08 & 1.885 \\
\hline $\begin{array}{l}\text { OPD II with } \\
\text { registration }\end{array}$ & 9 & 7 & 1.384 & 12.45 & 19.45 & 2.161 \\
\hline
\end{tabular}

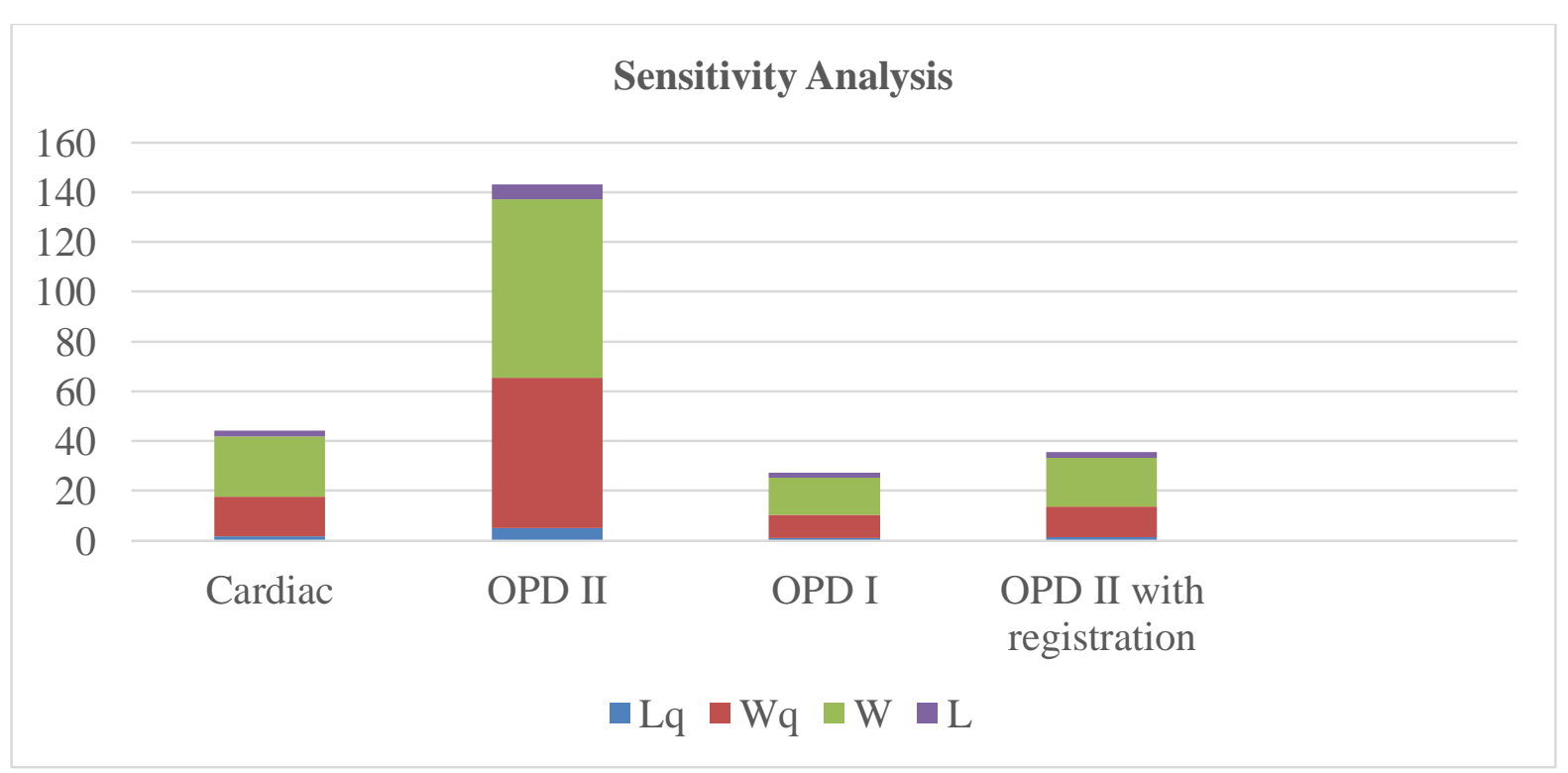

Figure 4 Graphical plot of results of sensitivity analysis 
From the results of the sensitivity analysis seen in Figure 4, OPD II without registration produces inferior performance compared to other OPDs. OPD I provide the optimal performance along with cardiac OPD and the change in time spent in the queue as we move from OPD II without registration to OPD II with registration is very appreciable. In addition, authentication of the results obtained was conducted by cross-checking the time registration system of OPD II wherein the waiting time in the system of OPD II post registration was calculated manually according to the flow of patients. It was found with $95 \%$ accuracy that waiting time according to our study was 19.45 minutes and manually calculated waiting time according to patient flow came out to be 20.6 minutes.

Based on the results obtained, it is found that first, the hospital lacks in having a proper system for letting patients know about registration especially the first-time visitors. There is wastage of time for the patient or their relatives in figuring out the exact procedures for the registration of new patients. Secondly, there were some minor technical errors such as improper placement of the registration form in the OPD main lobby, printer problem, etc. which added to the queuing challenge at OPD. Lastly, the signage indicating the counters for new registration, old registration, and golden age club patients were hanged little too high which makes it difficult for patients entering the hospital to read the signage and choose the queue accordingly which later created confusion and delayed the process. However, given the size and scale of the multi-specialty hospital, these were just a few indicators giving scope for improvement in the future.

\section{CONCLUSIONS, RECOMMENDATIONS, AND LIMITATIONS}

First and foremost, it is necessary to prioritize hospital operations according to the need, benefit and feasibility since the OPD coordinators find it difficult to keep track of patients, especially on Mondays, Thursdays, and Saturdays when there is high footfall. The registration forms must be placed near the new registration counter which should be made noticeable by bringing the signage a little down. Due to place constraints, not more than 2 attendants should be allowed per patient and guidance must be provided to the same for procedures expected as soon as the patient enters the main lobby. Queue managers can help in separating the patients into old and new and make sure no appointment is scheduled at the time of clinical rounds of consultants. The perceived waiting time can be reduced by providing facilities such as proper sitting arrangements, putting a TV, air conditioners, etc.

The most crucial element in increasing patient satisfaction in hospital operations is timely access i.e. "When" care is provided followed by "What" care is given. Waiting time plays a very crucial role in healthcare business and this study demonstrates the analysis and application of queuing theory in hospital operations for the improvement of process efficiency of OPDs. Patients' dissatisfaction associated with long waiting queues is well-known and the perceived waiting is much more annoying for the patients than the actual waiting time. The study has revealed that the subjective waiting time is highly co-related with the frustration of the patient than the objective waiting time. It is highly recommended to replicate the study in OPDs of other hospitals to verify the effectiveness of queuing theory for addressing queuing challenges faced by hospital operations in India.

Research focusing on the relative impact of word of mouth communication, personal needs and past experience on patients' service expectations in hospital operations within as well as across service categories can have useful managerial implications. Empirical research aimed at ascertaining whether, and in what ways patients service expectations differ will be valuable from a service marketers' viewpoint with regards to hospital operations and healthcare industry in general. The major insights gained through this study will hopefully spawn both academic and practitioner's interest in using queuing theory for service quality determination in hospital operations.

The morbidity pattern and thus the footfall may vary during the period of study since it was done for a confined time period. The emergency counter which also deals with the outpatients was not included in the study as there are patients of critical nature and they serve on a first come, first serve basis. In addition, in-depth interviews of the patients would have yielded a better understanding but due to time constraints and also considering the restless conditions of the patients it was deliberately avoided.

\section{ACKNOWLEDGEMENTS}

Hereby, the authors would like to express their sincere gratitude to the entire staff and management of Fortis Escorts Hospital, Jaipur for their support and co-operation.

\section{REFERENCES}

Adele, M., and Barry, S. (2005), Modelling patient flow in hospital using queuing theory, Unpublished Manuscript.

Bachmann, M.O. and Barron P. (1997), Why wait so long for child care? An analysis of waits, queues, and work in a South African urban health center, Tropical Doctor, 27(1), pp. 3438.

Bahadori, M., Mohammadnejhad, S.M., Ravaged, R. and Teymourzadeh, E. (2014), Using queuing theory and simulation model to optimize hospital pharmacy performance, Iranian Red Crescent Medical Journal, 16(3): ee16807.doi: 10.5812/ircmj.16807. [PubMed: 24829791].

Basta, Y.L., Tytgat, K.M., Klinkenbijl, J.H., Fockens, P. and Smets, E.M. (2016), Waiting time at a fast-track diagnostic clinic, International Journal of Health Care Quality Assurance 29(5), pp. 523-535.

Benson, R.J., Burnet, N.G., Williams, M.V. and Tan, L.T. (2001), An audit of clinic consultation times in a cancer center: implications for national manpower planning, Clinical Oncology 13(2), pp. 138-143.

Bleustein, C., Rothschild, D.B., Valen, A., Valatis, E., Schweitzer, L. and Jones, R. (2014), Wait times, patient satisfaction scores, and the perception of care, American Journal of Managed Care 20(5), pp. 393-400.

Bringedal, B., (2016) [Not Available], Tidsskr Nor Laegeforen., 136(1).

Broyles, J.R. and Cochran, J.K. (2007), Estimating business loss to a hospital emergency department from patient reneging by queuing-based regression, Proceedings of the 2007 Industrial Engineering Research Conference, pp. 613-618.

Carman, J.M. (1990), Consumer perceptions of service quality: an assessment of the SERVQUAL dimensions, Journal of Retailing 66(1), pp. 33-55. 
Cochran, K. J., and Bharti, A. (2006), A Multi-stage Stochastic Methodology for Whole Hospital Bed Planning Under Peak Loading, International Journal of Industrial and Systems Engineering 1(1), pp. 8-35.

Daulatani, Y., Kumar, S. and Vaidya, O. (2016), Improving OutPatient Flow at An Indian Ophthalmic Hospital, Operations and Supply Chain Management 9(1), pp. 15-21.

Dellaert, N., Cayiroglu, E. and Jeunet, J. (2015), Assessing and controlling the impact of hospital capacity planning on the waiting time, International Journal of Production Research 54(8), pp. 2203-2214.

Fiems, Koole, and P. Nain (2005) Waiting times of scheduled patients in the presence of emergency requests, Source: http://www.math.vu.nl/ koole/publications /2005report1/art.pdf, 2005.

Gorunescu, F., McClean, S.I. and Millard, P.H. (2002), A queueing model for bed-occupancy management and planning hospitals, Journal of Operations Research Society 53(1), pp. 19-24.

Green, L. V. (2002), How many Hospital Beds? Inquiry 37(4), pp. 400-412.

Green, L. V. (2006a), Queuing analysis in healthcare, in Patient Flow: Reducing Delay in Healthcare Delivery, (Hall, R.W. edition). New York: Springer, pp. 281-307.

Green, L.V. and Savin, S. (2008), Reducing delays for medical appointments: a queueing approach, Operations Research 56(6), pp. 1526-2538.

Green, L. V., Soares, J., Giulio, J., and Green, R. (2006), Using Queuing Theory to Increase the Effectiveness of Emergency Department Provides Staffing, Academic Emergency Medicine 13(1), pp. 61-68.

Gronroos, C. (1984), A service quality model and its marketing implications, European Journal of Marketing 18(4), pp. 3644.

Hall, R., Belson, D., Murali, P., and Dessouky, M. (2006), Modeling patient flows through the health care system, in Patient Flow: Reducing Delay in Healthcare Delivery, In Hall, R. Editor New York: Springer, pp. 1-44.

Hall, R., Belson, D., Murali, P., and Dessouky, M. (2013), Modeling patient flows through the health care system, In Hall R, editor. New York: Springer, pp. 3-42.

Hwang, J.I. (2006), Factors influencing consultation time and waiting time of ambulatory patients in a tertiary teaching hospital, Quality Improvement in Health Care 12(1), pp. 616.

Itumalla, R., Acharyulu, G.V.R.K., and Raja Shekhar, B. (2014), Development of HospitalQual: A service Quality Scale for Measuring In-patient Services in Hospital, Operations and Supply Chain Management 7(2), pp. 54-63.

Ivalis, S., and Millard, P. (2003), Health care modeling operating the black box, British Journal of Health Care Management 8(7), pp. 251-255.

Kay, E.J., Hough, D., and Blinkhorn, A.S. (1996), Operational research in the dental hospital setting an application of queuing theory, Journal of Dental Research 75(5).

Kilbourne, W.E., Duffy, J.A., Duffy, M., and Giarchi, G. (2004), The applicability of SERVQUAL in cross-national measurements of health-care quality, Journal of Services Marketing 18(7), pp. 524-533.

Kim, S., Horowitz, I., Young, K., and Buckly, T. (1999), Analysis of Capacity Management of the Intensive Care Unit in a Hospital, European Journal of Operational Research 105, pp.36-46.

Kim, S., Seo, H., Lee, J., Kwon, Y., Kim, S. and Park, I. (2009), An application of a queueing network for waiting for time reduction at the emergency care center, Proceedings of the Korean Operations and Management Science Society Conference, pp. 298-316.
Kim, S., Son, U., Choi, J., Roh, J. and Yang, Y. (2008), Analysis of factors delaying on waiting time of outpatient in a general hospital, Health Welfare 10, pp. 107-120.

Ko, Y.K. (2010), The relationships among waiting time, patient's satisfaction, and revisiting intention of outpatients in general hospital, Journal of Korean Academy of Nursing Administration 16(3), pp. 219-228.

Koizumi, N., Kuno, E. and Smith, T.E. (2005), Modeling patient flows using a queuing network with blocking, Health Care Management Science 8(1), pp. 49-60.

Komashie, A., Mousavi, A., Clarkson, P.J. and Young, T. (2015), An Integrated Model of Patient and Staff Satisfaction using Queuing Theory, IEEE Journal of Translational Engineering of Health and Medicine.

Kritchanchai, D. (2012), A Framework for Healthcare Supply Chain Improvement in Thailand, Operations and Supply Chain Management, 5(2), pp. 103-113.

Lewis, and Mitchell (1990) Defining and Measuring the Quality of Customer Service, Marketing Intelligence \& Planning 8(6), pp. 11-17.

Lewis, Robert C. and Bernard H. Booms (1983), The Marketing Aspects of Service Quality, in Emerging Perspectives on Services Marketing, L. Berry, G. Shostack, and G. Upah, editions., Chicago: American Marketing, pp. 99-107.

Lohlun, K.N., Kotzen, J.A. and Lakier, R. (2015), A prospective study on the impact of waiting times for radiotherapy for cervical cancer at Charlotte Maxeke Johannesburg Academic Hospital, South African Journal of Obstetrics and Gynaecology, 21(1), pp. 6-9.

Mandelbaum, A., Momcilovic, P. and Tseytlin, Y. (2012), On fair routing from emergency departments to hospital wards: QED queues with heterogeneous servers, Management Science 58(7), pp. 73-91.

Mayhew, L. and Smith D. (2008), Using queuing theory to analyze the government's 4-H completion time target in accident and emergency departments, Health Care Management Science 11(1), pp. 11-21.

Murray, S. C. (2000), Understanding the Patient Flow, Decision Line.

McQuarrie, D. G. (1983), Hospital utilization levels. The application of queuing theory to a controversial medical economic problem, Minnesota Medicine 66, pp. 679-686.

Natarajan, R. N. (2006), Transferring best practices to healthcare: opportunities and challenges, The TQM Magazine 18(6), pp. 572-582.

Natchair, G., Robin, A. L., Thulasiraj, R. D., and Krishnaswamy, S. (1994), Attacking the backlog of India's curable blind: the Aravind Eye Hospital model, Archives of Ophthalmology 112(7), pp. 987-993.

Ozcan, Y. A. (2006), Quantitative methods in health care management, Techniques and applications (First edition) Jossey-Bass Publications.

Parasuraman, A. Zeithaml, V.A., and Berry, L.L. (1985), A conceptual model of service quality and its implication, Journal of Marketing 49, pp. 41-50.

Parasuraman, A., Zeithaml, V.A., and Berry, L.L. (1988), SERVQUAL: a multi-item scale for measuring consumer perceptions of the service quality, Journal of Retailing 64(1), pp. 12-40.

Parasuraman, A., Zeithaml, V.A., and Berry, L.L. (1991), Refinement and reassessment of the SERVQUAL scale, Journal of Retailing 67(4), pp. 420-450.

Park, CS, and Koh, SH. (2011), A case study on the improvement of general hospital outpatients waiting time using TOC methodology, Korean Journal of Hospital Management, 16(1), pp. 77-100.

Park, CK. and Kwag, EJ. (2009), A case study about managing waiting time for raising customer's satisfaction in the medical service, Korean Journal of Hospital Management, 14(3), pp. 132-153. 
Park, SH. (2001), Analysis of factors delaying on waiting time for medical examination of outpatient on a hospital, Journal of Korean Society Quality Assurance Health Care 8(1), pp. 5672.

Siddhartan, K., Jones, W. J., and Johnson, J. A. (1996), A priority queuing model to reduce waiting times in emergency care, International Journal of Health Care Quality Assurance 9, pp.10-16.

Van Wyk, R., and Walubo, A. (2014), The use of queuing theory and patient-based characteristics to assess the Performance of the Paediatric Intensive Care Unit at University as Academic Hospital in South Africa, Basic \& Clinical Pharmacology \& Toxicology, pp.115-235.
Vasanawala, S. S., and Desser, T. S. (2005), Accommodation of requests for emergency US and CT: Applications of queuing theory to the scheduling of urgent studies, Radiology 235, pp. 244-249.

Worthington, DJ. (1987), Queueing models for hospital waiting lists, Journal of the Operations Research Society 38(5), pp. 413-422.

Yeo, H., Bak, W., Yoo, M., Park, S., and Lee S. (2014), Evaluation of patients' queue environment on medical service using queueing theory, Journal of the Korean Society of Quality Management 42(1), pp. 71-79.

Deepak Yaduvanshi is Chief Consultant \& Incharge of Department of Respiratory, Sleep Disorder \& Critical Care Medical services at Manipal Hospitals in Jaipur. He is trained in healthcare systems with a focus in hospital Management Operations. He holds a master's in Hospital Administration from BITS Pilani \& Bombay Hospital, also winning the prestigious FICCI Healthcare Excellence award for operational Excellence on Six Sigma. His background is rich in diversity having worked as Medical Director with the largest flagship PPP Project - Metro Hospital Jaipur, Government of Rajasthan. He has been the keynote speaker and on the advisory board of GSK, Abbott, and Pfizer besides being, Principal Investigator in numerous clinical \& Epidemiological Trials including FDA supported H1N1 Study and worked closely with industry associations like CII for initiatives in Healthcare Industry.

Ashu Sharma is Associate Professor and Program Chairperson of Executive MBA at Narsee Monjee Institute of Management Studies (Deemed-to-be-university), Mumbai. She has worked as the Chairperson for MBA(FT) Programme, Faculty Coordinator for Placements of Management students and Coordinator for FDPs at JK Lakshmipat University, Rajasthan. She has presented papers in several National and International conferences organized by reputed institutions; such as Churchill College, Cambridge University, London, Monash University, Australia, XLRI, Jamshedpur, IIM Ahmedabad, IIM Bangalore, Shanghai Jiaotong University (SJTU), Shanghai, China, Milagrow- World SME Conference, Operational Research Society of India (ORSI), Production \& Operations Management Society, Jamnalal Bajaj Institute of Management Studies, Korean Data Base Society and UGC National Conference. She has published her works in refereed and open access journals like IJTD, SSRN, Scopus, ABDC, Excel Publishers, etc. She has conducted Management Development Programmes for Senior Managers of L\&T, JK Cement, Ericsson, JK Tyre, JK Paper, BKT Tyres, GAIL, etc.

Praful Vijay More is a full-time research scholar at School of Business Management, Narsee Monjee Institute of Management Studies (Deemed-to-be-university), India. He has completed bachelor's in chemical engineering from Pune University and master's in management studies from Mumbai University. He has presented several papers in international conferences held at IIT Bombay, IIM Kozhikode, IISc Bengaluru, etc. and has participated in summer schools in Europe and Thailand. His research interest includes Operations Management, Healthcare Services, Hospital Management, and Public Health. 